\title{
4. The Mutability of Time and Space as a Means of Healing History in an Australian Aboriginal Community ${ }^{1}$
}

\author{
Rob Paton
}

The poet Seamus Heaney in his famous work Bogland ${ }^{2}$ speaks to the connection of the Irish people to their land:

Every layer they strip

Seems camped on before.

The bogholes might be Atlantic seepage

The wet centre is bottomless

He imagines Ireland's peat bogs to be a timeless, bottomless land that has forever been camped on. For Heaney, these bogs are as deep and mysterious as the ancient Irish whose archaeological relics are uncovered by modern-day peat miners who strip away the layers. Of course, we know Ireland's peat bogs are neither timeless nor bottomless. Scientists have shown that they are relatively recent landscape features. But we also know Heaney's imagined bogland is poetic country. In this country, time and space are allowed to be used and changed to tell us a story about people and their profound attachment to their homeland. But most of us live in different countries from poets. In the academy, or at least in the historic disciplines in which many of us operate, we are not as flexible as poets with time or space. Most of us perceive time as linear, moving from the past to the present in a straight line, with events occurring in a roughly ordered fashion relative to one another in time and space. This suits most of us. It is how we lead our lives and how we structure our stories about the past. ${ }^{3}$ But for scholars engaged with Aboriginal histories, the architecture of linear history, while sometimes a useful tool, is perhaps just as deeply imaginary as Seamus Heaney's poetic country.

\footnotetext{
1 Thanks to the Mudburra and Jingili people who worked with me over a 30-year period. I acknowledge their generosity in giving me permissions to share their culture and insights with others. I am particularly indebted to my good friend Nuggett Collins Japarta and his family. I would also like to thank my supervisor Professor Ann McGrath, who encouraged me to write this paper and gave freely of her time and knowledge. Denis Byrne and Maria Nugent read drafts of the paper, and I thank them both for their insightful comments. The content of the paper is entirely my own, except where otherwise acknowledged.

2 Heaney 1969.

3 Price 1997.
} 
We readily accept that our colleagues from other academic disciplines see time and space operating very differently to the conventional linear model. Western cosmologists, for example, see space and time as a continuum called 'space-time' that can be warped and changed. ${ }^{4}$ It should not come as a surprise then that some other cultures, those of Aboriginal Australians, also recognise time and space in ways very different to the linear model. When dealing with space, historians and archaeologists like Read, ${ }^{5}$ Harrison, ${ }^{6}$ and Byrne and Nugent ${ }^{7}$ have in the past decade or so made strong cases for other human geographies, recognising that Aboriginal space exists alongside European geographies in urban and rural environments.

Cross-cultural perceptions of time, however, have received a somewhat confused treatment in the literature. In the context of Aboriginal Australia, when we come to consider how time operates, we are usually drawn to concepts of the Dreamtime. While acknowledging the 'timelessness' of the Dreamtime, scholars have nevertheless attempted to historicise it, likening the Dreamtime to a kind of quasi-religious Aboriginal history. ${ }^{8}$ This treatment is analogous in some senses to the plethora of attempts to rigorously historicise the Bible. While such attempts have been met with varying success, in its crudest form we have seen Bishop Ussher, in 1648, dating the beginning of the world to Sunday, 23 October 4004 $\mathrm{BC}$, primarily by analysing the ages of individuals and the reigns of kings in the Bible. ${ }^{9}$ I would argue that by too closely linking the Dreamtime to Aboriginal history, we are perhaps also in danger of contriving fables that occasionally, and for the most part serendipitously, triangulate to factual data. This is not to deny the significance of the Dreamtime within Aboriginal societies. Nor does it downplay the debates around the nature, role and efficacy of the Dreamtime for researchers. ${ }^{10}$ Rather, my argument is that by considering the role of more secular concepts of Aboriginal time, newer perceptions can emerge similar to the human geographies of Aboriginal space that we now acknowledge as part of the Australian landscape.

How time and space are imagined by Aboriginal people is as sophisticated as it is varied. My intention here is simply to look at a case study from the Top End of the Northern Territory, showing how one group imagine their time and space. Through a detailed example, I will show how the gravity of one very hurtful

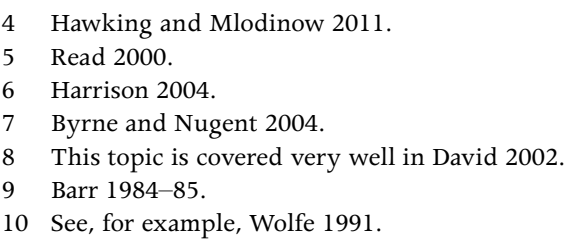


event involving several deaths was perceived by the Aboriginal community, and how they came to resolve it by engaging the inherent mutability of secular time and space in order to rewrite the past.

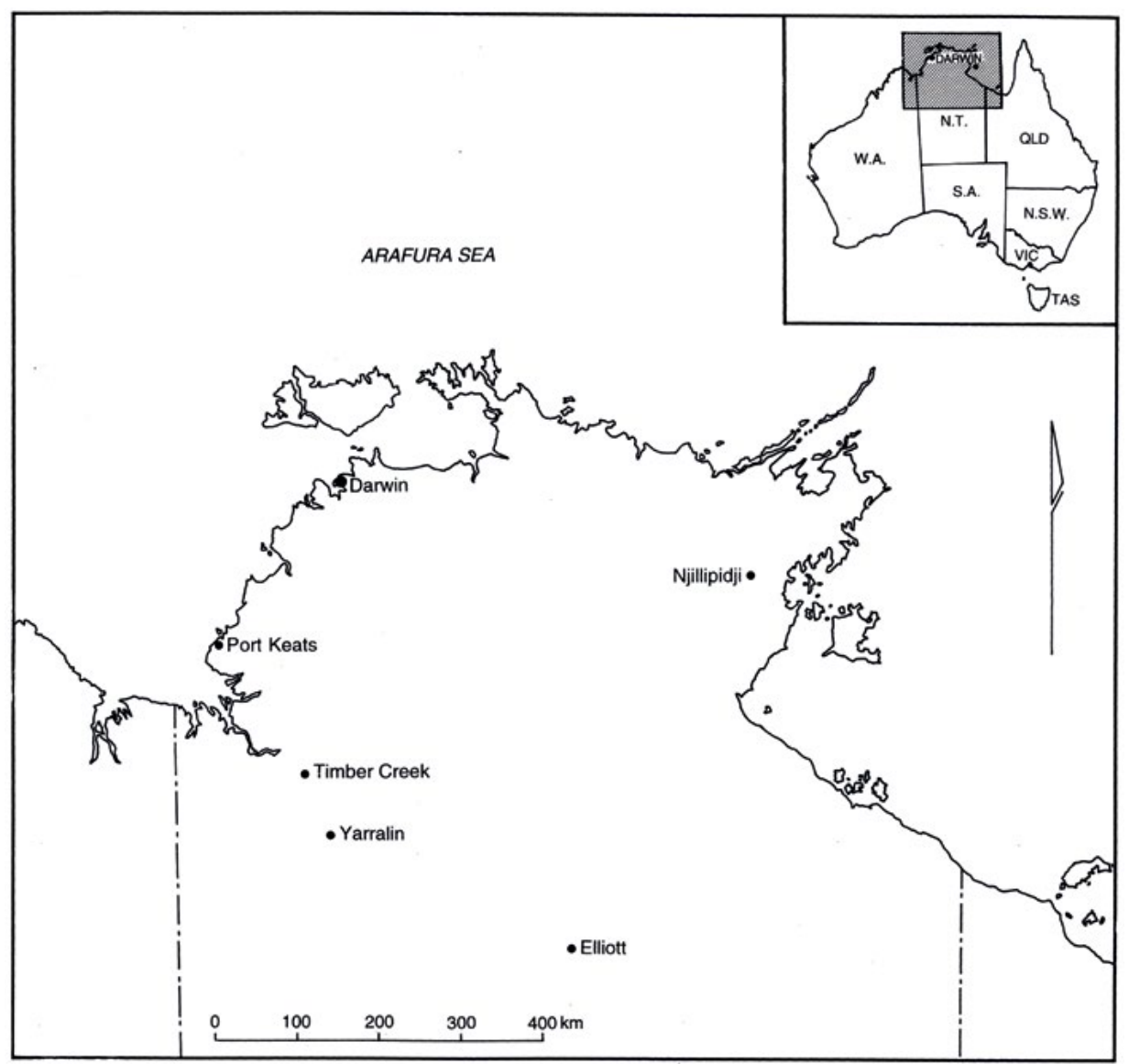

\section{Figure 4.1: Map of northern Australia showing places mentioned} in the text.

Source: Robert Paton Collection.

The event I look at occurred near Elliott, a small settlement of several hundred, mostly Aboriginal, people in the central Northern Territory (Figure 4.1). In the summer of 1985-86, a small party of people left Elliott to hunt on the vast Newcastle Waters cattle station. They headed about 50 kilometres north-west into harsh, inhospitable country mostly devoid of any standing water. Led by highly experienced bushmen and women, the party had planned to hunt and camp and then return home after a day or so. But when nothing was heard from them after a few days, concerns began to be raised. However, it was still assumed at this point that these experienced people could handle most situations. 
Their family and friends at the small Aboriginal community at Elliott, which they had left days earlier, had no idea about the life and death drama unfolding some 50 kilometres away.

By the time search parties were sent out a short time later, all of the group were dead, and had been for some time. The police report details a sad account of the small family car in which they were travelling breaking down on an isolated farm track. In the extreme heat, members of the party had apparently sought water at a nearby artesian bore. They could not have known that the water at the bore contained high levels of bacteria. The more water they drank, the sicker and more dehydrated they became. The vicious combination of 40 degree heat, thirst and sickness eventually overcame the group. Their bodies were found at various distances from the bore. It was surmised that as the weaker members of the group died close to the bore, the stronger individuals, realising that the water was making them sicker attempted to walk out for help. By then it was too late. In their fragile state, and probably suffering from delirium, they walked in different directions until eventually they simply fell and died. ${ }^{11}$

The effects of heat and scavenging animals on the bodies was particularly distressing for the local Aboriginal Police Trackers who first came across the tragic scene. Stories about what the Trackers had found and reports from relatives who formally identified the bodies swept through the community. Rumours abounded about what had caused the deaths. People said that witnesses had seen bullet holes on the bodies, and that the authorities were falsely reporting these as the effects of heat and animals. Suspicions about who had killed the family began to circulate and there was a widely held belief that something 'unnatural' had happened. ${ }^{12}$

I arrived in the community a few months after the deaths to undertake some archaeological research. I had been working with this community for a number of years and I was shocked to see how the tragic and perceived unnatural manner of these deaths had left the community in the grip of a moribund lassitude, well beyond the ordinary grieving experience. The normally close-knit community began to fracture, with some families moving away to nearby settlements and other people isolating themselves from important communal responsibilities. As a result, nearby communities began to see the settlement at Elliott as 'diseased'. This diseased state was also seen to be uncontained and spreading. Strings of mythological creation sites and stories that connected Elliott to the surrounding communities were said to have become infected. These sites and

11 See taped interview (Longreach Winnun 24 June 1986, 16:32 to 18:45) at deepeninghistories.anu.edu.au/ sites/pelican-dreaming/ and NT News January to March 1985 passim.

12 See taped interview (Longreach Winnun 24 June 1986, 16:32 to 18:45), deepeninghistories.anu.edu.au/ sites/pelican-dreaming/. 
the stories attached to them form an important part of what Aboriginal people refer to as 'Dreaming histories' or creation myths. All relationships between people, and between people and the land, are intimately tied in some way to these Dreaming histories. They form part of the fabric of the cosmos. So this was an extremely serious situation.

As the months passed, community elders attempted to cope with this great sorrow by managing the space of their settlement. They abandoned the houses where the deceased had lived. Most of the personal possessions of the deceased were destroyed and their names were not referred to directly. These sorts of customs that deal with living space are well documented in Aboriginal communities and are generically known as part of 'sorry business'.$^{13}$ They are usually maintained for a year or so, or in some northern communities until the monsoonal rains arrive to wash away the sorrow. But for the Aboriginal community at Elliott, management of their living space seemed to have limited impact on the great sorrow. The community remained in the grip of grief. Those remaining at the settlement hardly ventured outside of their homes; there was talk of cancelling important initiation ceremonies planned for later that same year.

For most of us who have dealt with terrible grief like this, we are comforted by the knowledge that time will heal. We recognise that linear time distances us from hurtful events. In this sense, the cliché that 'time heals' often has some efficacy. But as I have hinted, not all cultures, or scholars, imagine time in this way.

For many Australian Aboriginal communities, linear time is perceived to have a depth of only a generation or two. This linear time exists along with what I call 'temporal wave time'. In temporal wave time all events exist alongside each other on a flat temporal plain, like the face of a wave that moves forward, capturing all history as it progresses. People certainly also see time as working in other ways - linear, and in categories like 'cattle time' or 'rain time'. But the main way of perceiving time is as this flat, wave-like structure. Others ${ }^{14}$ have commented on this view of time, referring to instances where relatively modern events enter this wave of progressing time and become incorporated into it - the Cigarette Dreaming, the Toyota Dreaming and the Captain Cook Dreaming. ${ }^{15}$ As the names imply, scholars have tended to lump these events together with Dreamtime creation myths because the two exist on the flat temporal plain alongside one another. But events on the flat temporal plain are not all the same. They do not all have the same gravity, nor are they all associated with religious creation events. Day-to-day secular events are compartmentalised (in the sense of being

13 www.indigenousaustralia.info/culture/mourning-ceremonies.html.

14 Rose 1992.

15 See, for example, Rose 1984; Hokari 2011: 254-260. 
discrete), as are creation stories, though any event may link to another through song, myth or physical tracks. This linkage is reported most often for Dreamtime creation myths (such as along Songlines). But day-to-day secular events may also affect other events across the temporal wave, depending on their gravity.

It is for this reason that very hurtful and tragic events like the deaths described earlier can attain a constancy in these communities, and a gravity that disrupts other events on the temporal wave. And this is what was happening in Elliott. The severity of the hurt caused by the multiple deaths was too overwhelming to be dealt with by actions like the abandonment of houses and the destruction of dead people's property. No temporal distance was being created between the deaths and the immediate lives of people. Moreover, the magnitude of the events surrounding the deaths was eclipsing everything else on the flat temporal plain. And this was unlikely to resolve itself as the wave of time moved forward, meaning the event remained unresolved and ever-present.

It is important to understand that the hurtful event was not just confined to the temporal dimension. It also affected places across the landscape, much further afield than the domestic spaces that were abandoned or destroyed to help remove the pain as part of 'sorry business'. This is because both time and space are indelibly locked together in the temporal wave through Dreaming history stories. These stories about the creation of the cosmos exist, like all things, on the flat temporal wave, constantly and immediately. The stories can also be influenced (and sometimes consumed) by other large events that may appear suddenly on the temporal wave. The crucial connection of these Dreaming history stories to places in the landscape was made clear in a conversation I participated in and recorded at a site called Kankiritja. The conversation explains some of the general unrestricted Dreaming stories associated with the site and the much wider landscape. These Dreaming stories, as I have discussed elsewhere, ${ }^{16}$ help explain the creation of large geological outcrops of quartzite that form the backbone of one of the main ranges around Elliott. Within these outcrops are massive stone quarry sites, where for many centuries people manufactured large stone knives. The names of the two men talking are Nuggett Collins Japarta (NC) and Abby Thomas Jungala (AT). The taped conversation that relates unrestricted information was recorded in $1985 .{ }^{17}$ It has been edited slightly to remove some irrelevant material and to help clarify points.

16 Paton 1994.

17 For a full account of this conversation on video see deepeninghistories.anu.edu.au/sites/pelicandreaming/index.php?action=video. 
AT: Pelican you call him. We call him wallambee.

NC: That's where they been comin' here [pointing around to the quartzite outcrops]. Land on this place. That why they call Kankiritja [means pelican landing place].

AT: Kankiritja this one now. That's his knife [pointing to a blade]. Pelican been have this. Cut anything or kill someone. And he used to have that spear, that mouth he got now, that pelican [showing how two blades, one on top of the other, makes the shape of a pelican's beak].

NC: That's the one pelican Dreaming, this one [points to a blade]. Pelican been come in, land here. Well this is the stone he made.

AT: He made him for knife. We call him giru [local name for the leilira blade].

NC: Three names; giru, jabiri, marubu [different languages]. This one now. Pelican been land here. Oh, big mob. Million. That why the hill over there. That why the big hill right there, round and round. All this, all the way along. Some over there where we went this morning. This way. Keep going thataway and some big hill there now. This a pelican Dreaming. That's why he been come in. Make Dreaming stone.

AT: Yeah. Some all through. And that [fire for burning stone] come down from that way [pointing north-west]. That's them two sparrowhawk. Sparrowhawk sing out kiri kiri kiri kiri kiri kiri kiri. He sing out like that. That's the one been made it. From our country ... They [the pelican] been bringing this [the blades] and that people [the two sparrowhawks] used to been using the fire sticks. They been bad eh? Some two been comin' along, they had him here. They been gone give it that fire stick on to them here ... Ah that good man. That's what we gotta do now, all do.

The linking of important Dreaming history stories that exist on the temporal wave to places in the landscape is well illustrated by the two Aboriginal men in the recording. But how can such stories be influenced by significant, though apparently unrelated, hurtful events like the deaths? One way of conceptualising this is to imagine the Dreaming stories to be like a bright star casting light onto the landscape, illuminating its features. Then imagine a body of immense gravity, like a black hole, suddenly appearing near the star, capturing its light, and in the process warping both time and space and distorting reality. Such a destructive event, if left unresolved, would clearly continue to play havoc with the cosmos, far beyond its own borders. 
When it became clear after several months that the hurt caused by the deaths would not resolve, people began to discuss how they might heal the community by breaking the link between these very sad historic events and their own immediate lives. A decision was made about six months or so after the deaths to engage an elegant mechanism called winnun to help heal the temporal wave. ${ }^{18}$ Winnun in its most basic manifestation involves trade of material objects. However, it is much more than this. Winnun is best understood as it was described to me; as being like blood circulating in a body. Carried within the blood are all of the things necessary to keep an organism alive and healthy. In this sense, the objects traded in winnun are not in themselves as important as what they carry. These objects are embedded with special meanings that are exchanged with the objects as a way of rewriting community memories and healing the past.

In this instance, the winnun ceremony involved an exchange of boomerangs made in Elliott for items from the Aboriginal settlement at Yarralin, 325 kilometres to the north-west. From Yarralin the exchange was to be continued through to Port Keats a further 275 kilometres away (see Figure 4.1). The idea behind the winnun exchange was to help heal the community through initiating an event which would demonstrate to others that the stigma associated with the deaths had been overcome. The exchange was initiated through a series of telegrams and telephone calls. Arrangements were made for some bamboo spears to be flown by light aircraft from Port Keats to Yarralin via a small settlement near Yarralin called Timber Creek.

It was decided after negotiations that certain boomerangs with attached Dreaming stories would be traded from Elliott in exchange for the spears. The people at Yarralin had arranged for some of the boomerangs to be flown to Port Keats after the exchange had taken place at Yarralin.

The whole process of this winnun cycle took between two and three months to complete, and I was fortunate enough to be living with the community for this time, working with people to collect the wood for the boomerangs.

The wood was gathered over several weeks by men, women and children. The type of wood used for boomerang manufacture grows abundantly throughout the area. However, trips were never made to the nearest or most accessible sources of timber. Furthermore, even though the areas visited on the first trips contained ample wood to make return visits attractive, such visits were never seriously considered. The rationale behind this strategy seems to contain two elements. Firstly, people went to trees or places that were connected to Dreaming stories and that were said to have been 'diseased', or infected,

18 McGrath 2014. 
by the deaths. Each boomerang, as it was made, was said to absorb elements of this diseased Dreaming story. For this reason, people said it was important that each boomerang be called a particular name and be kept separate from all the others. A second, and equally important reason for making an apparently simple procurement task more complicated, was the extended time it allowed for discussion between the people collecting the wood. Each trip involved many hours of talk about the forthcoming exchange and the healing this would bring back to the community.

Thirty boomerangs were made and covered in a red ochre which had been quarried to the south and traded to Elliott in a related but separate winnun exchange. The bundles were tied together; three bundles of seven and one of nine. The bundles were then driven about 300 kilometres to Yarralin, an Aboriginal settlement on the Victoria River. Shortly after, 20 to 30 local men arrived for discussions. A car then arrived carrying a bundle of 17 bamboo spears that were exchanged for the bundles of boomerangs. Some more discussion occurred and a bolt of red cloth was added to the spears as payment for the boomerangs. Both the cloth and the spears were then loaded onto our truck and within 10 minutes we departed.

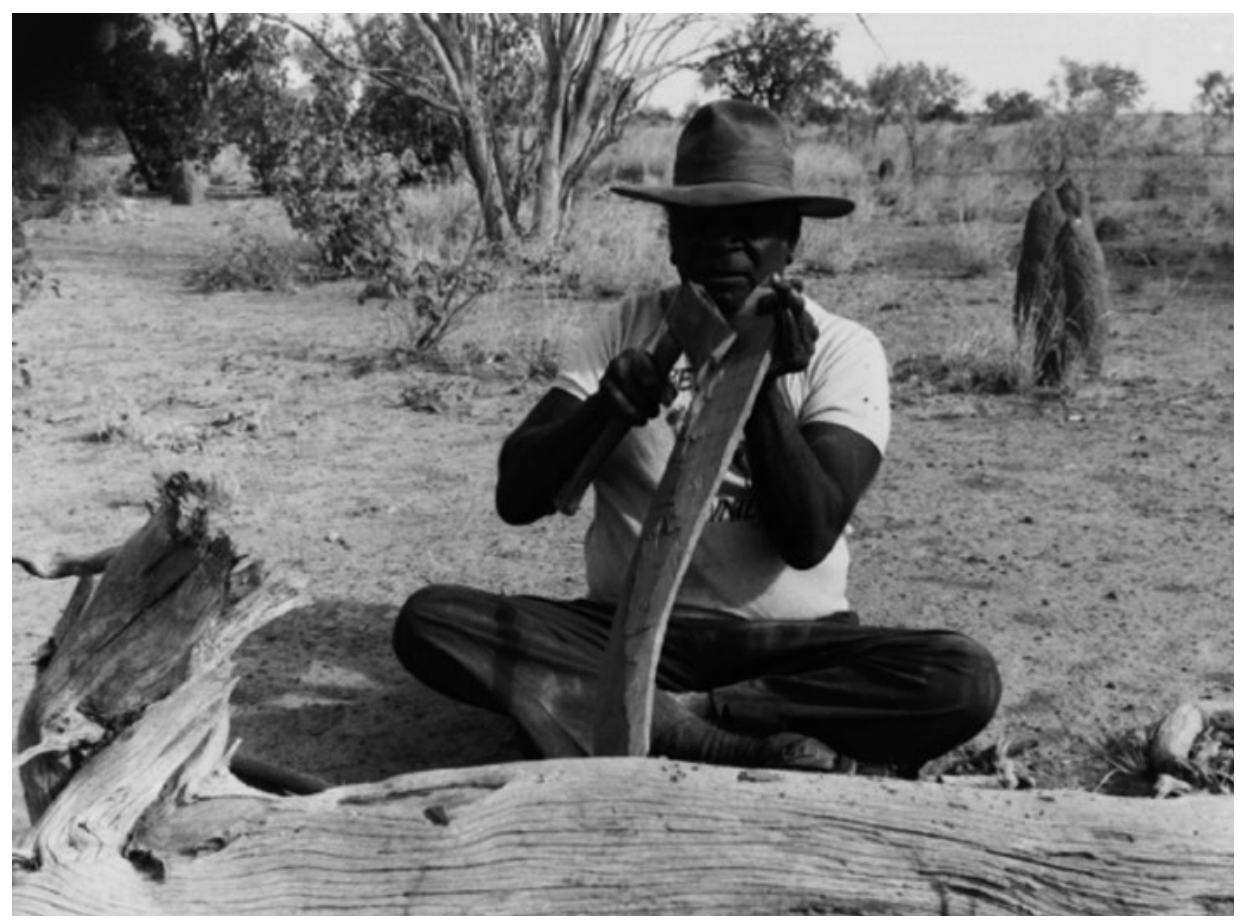

Figure 4.2: Nuggett Collins Japarta making boomerangs for the winnun exchange, circa June 1986.

Source: Robert Paton Collection. 


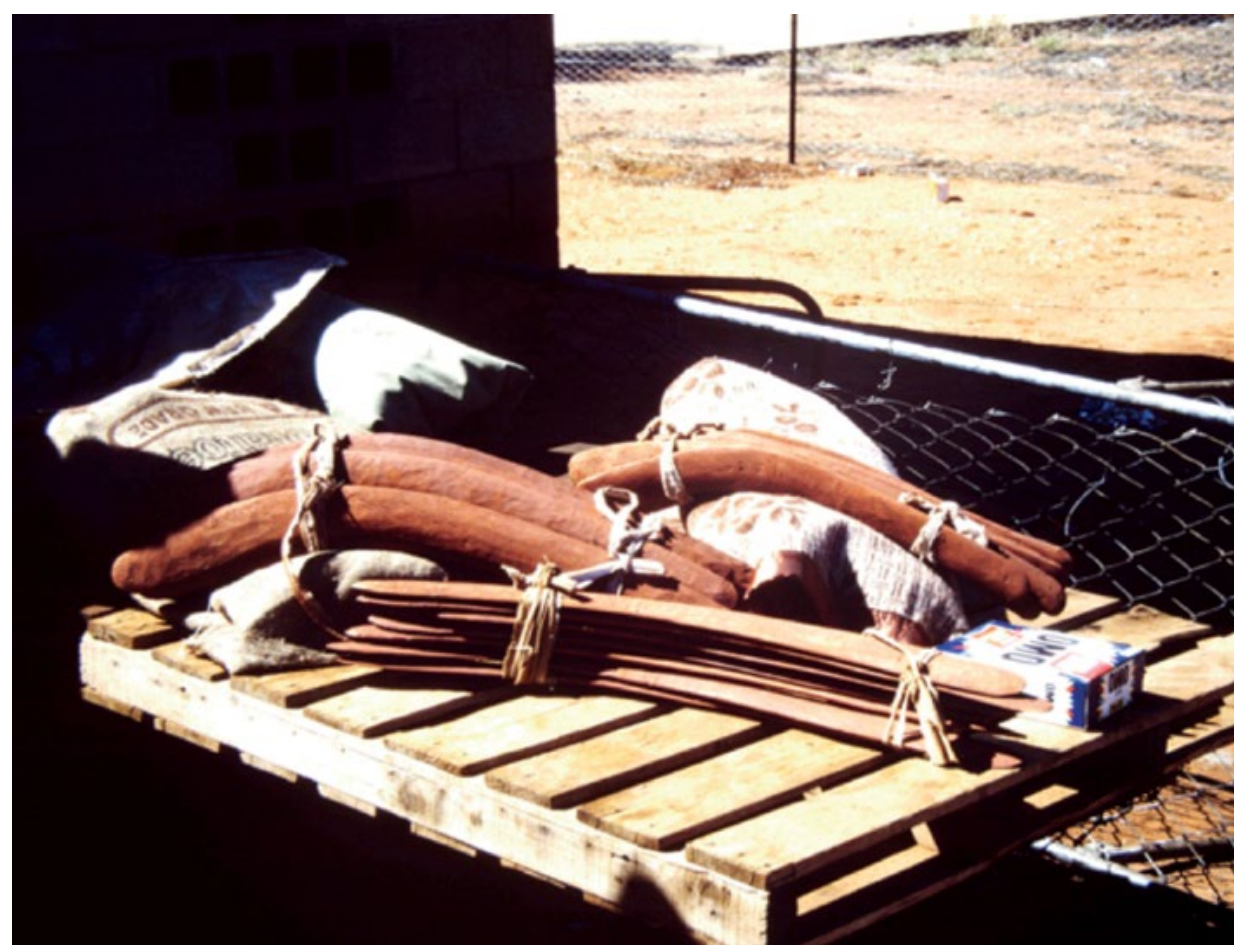

Figure 4.3: The bundles of ochred boomerangs ready for exchange, circa June 1986.

Source: Robert Paton Collection.

On return to Elliott, the spears and the cloth were divided amongst the men and women who had made the boomerangs or collected the wood. Shortly after, these items were deliberately destroyed or sold to European tourists, effectively removing them from the community. Similarly, the boomerangs that I was able to trace at the other end of the winnun trade cycle were also deliberately destroyed. To further illustrate this point, one of the men from Elliott was given a Kung Fu video cassette as part of another exchange (the exchange further to the south to obtain red ochre to apply to the boomerangs). ${ }^{19}$ This occurred despite the fact that nobody at Elliott had a video cassette player. This point was discussed during the exchange, but in the end was not considered to be important. The cassette was left out in the sun and then later thrown in the sand and presumably destroyed, having served no utilitarian function at all. 


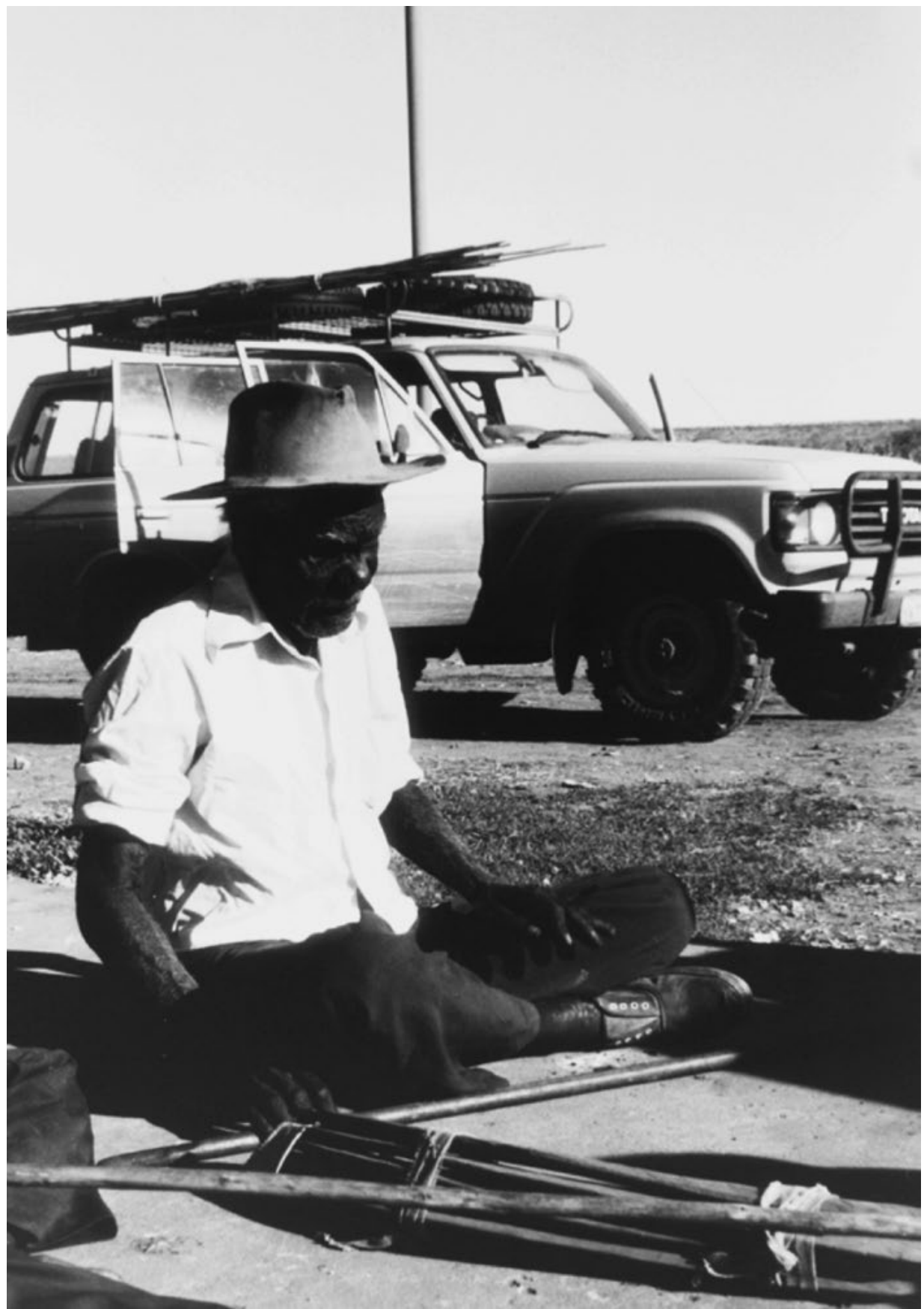

Figure 4.4: The winnun exchange taking place at Yarralin Aboriginal community, circa July 1986 . One of the bundles of boomerangs is in the foreground and the bamboo spears are tied to the roof of the truck.

Source: Robert Paton Collection. 
The destruction of the winnun goods had an almost immediate effect on the community. People moved back to the settlement and the community began to rapidly heal from the hurt the deaths had brought. The clearest manifestation of this was the resumption of men's and women's initiation ceremonies that had been suspended after the deaths almost nine months before. People were also able to speak about those events with a tone of quiet resolution. The accusations of blame for the deaths had been completely resolved and the gravity of the incident was palpably dissipated, albeit still ever-present. It seems that the winnun trade items, although inanimate objects, were infused with the gravity of the deaths and then were deliberately discarded as a means to rewrite history and heal a great hurt.

Though poignant, this example of reshaping the past through the winnun cycle is, I suggest, not an isolated or exceptional case. Management of events on the flat temporal wave occurs constantly, both at a local level and much further afield. Moreover, it appears that winnun is very old. It can be traced in the deep prehistoric archaeological record, where for thousands of years people's memories took the shape of healing objects that were reshaped to rewrite the past. My research ${ }^{20}$ has shown that large stone knives called leilira blades once formed the backbone of a winnun system that covered most of the Top End of Australia, stretching from the Arafura Sea south to Alice Springs, and from western Queensland to the Kimberley Ranges in Western Australia. ${ }^{21}$ These leilira blades were manufactured in their millions at massive stone quarries. ${ }^{22}$ They were elaborately named, bundled and traded over vast distances, often for morphologically identical blades. Once exchanged, they were then deliberately destroyed. I have argued elsewhere that the material signature of the winnun network is widespread across Australia, sometimes comprising up to a quarter of the artefacts found at archaeological sites. ${ }^{23}$

20 Paton 1994. See also Thomson 1949; Jones and White 1988.

21 Paton 2013, deepeninghistories.anu.edu.au/sites/pelican-dreaming/.

22 For example, at one leilira blade quarry near Katherine there are approximately 45 million stone artefacts. Eleven per cent of these (nearly 5 million) are estimated to be leilira blades. Several similar quarries have been recorded by me near Elliott. See Paton 1995.

23 Paton 1994. 


\section{Conclusion}

To conclude, I would like to return to Seamus Heaney's poem Bogland.$^{24}$ Like the Aboriginal people whose story I have told here, Heaney sees both the infinity and immediacy of time in the landscape, and in objects from the past. He expresses this when he writes about the bogs being the receptacle of memory, conserving and linking the deep past and present.

Butter sunk under

More than a hundred years

Was recovered salty and white

He also sees the bog as being 'kind', melting away to reveal its secrets.

The ground itself is kind, black butter

Melting and opening under foot

I hinted, at the beginning of this chapter, that perhaps those who research Aboriginal Australia should reflect upon how poets like Heaney imagine the past. Scholars have certainly done so in the area of human geography, where Aboriginal landscapes have been resolved into focus even in the heart of Australia's major cities. But conventional temporal discourse continues to remain largely driven by the academic disciplines, particularly archaeology, which seems the most conservative. I do not think we in the academy are any more 'right' about our view of time than Aboriginal people about theirs, other than that it makes writing linear chronologies of the past easier. ${ }^{25}$ It might suit historians dealing with the modern period. ${ }^{26}$ But for those of us who research the deep past, particularly that past as experienced and understood by Indigenous people, a fuller discussion of the discourse seems useful. I am reminded of a story by Denis Byrne ${ }^{27}$ who, like me, when working as an archaeologist was often confronted by Aboriginal people who had an appreciation of our archaeological view of the past, yet could not understand why archaeologists did not reciprocate. Denis's story shifted my own view of this temporal discourse enough for me to write this chapter. It also made me understand some of the consequences that might flow from these discussions. For example, when museums return objects to Aboriginal communities, perhaps they should consider if these objects (although chronologically old in linear time) are part of a winnun cycle and have agency beyond their material value. By originally giving them to collectors, were these objects being disposed of?

24 Heaney 1969.

25 Rosenberg and Grafton 2010.

26 Shryock and Smail 2011.

27 Byrne 2013. 
Returning them could potentially reignite the hurt embedded in the object, regardless of its age in linear time. Similarly, heritage managers, charged with attributing significance to Aboriginal sites and objects, do so via legislation that focuses on slices of linear time. They usually attribute greater significance to those sites and objects that have been scientifically calibrated to be older. Germane as this may be to archaeologists, it often has little meaning for many Aboriginal people who do not see the past as consisting of scientific material, locked statically in deep linear time.

When I began this research some three decades ago, my focus was on the economic and social 'chain of connection'28 along Aboriginal trade routes, through slices of linear time - and this continues to be the way these trade systems are portrayed in recent archaeological publications. ${ }^{29}$ But it was the obvious intimacy that people had with objects from the deep past that in the end shaped my own thinking. ${ }^{30}$ The deep past began to collapse into the present, revealing an abiding temporal chain of connection that was more important than any material objects in themselves.

\section{Bibliography}

Barr, James 1984-85, 'Why the world was created in 4004 BC: Archbishop Ussher and Biblical chronology', Bulletin of the John Rylands University Library of Manchester 67: 575-608.

Byrne, Denis 2007, Surface Collection: Archaeological Travels in Southeast Asia, Altamira Press, New York.

Byrne, Denis 2013, 'Looking for difference in the Aboriginal contemporary past', in Rodney Harrison, Paul Graves-Brown and Angela Piccini (eds), Oxford Handbook of the Archaeology of the Contemporary Past, Oxford University Press, Oxford.

Byrne, Denis and Maria Nugent 2004, Mapping Attachment: A Spatial Approach to Aboriginal Post-contact Heritage, Department of Environment and Conservation NSW, Sydney.

David, Bruno 2002, Landscapes, Rock-art and the Dreaming: An Archaeology of Preunderstanding, Leicester University Press, London. 
Harrison, Rodney 2004, Shared Landscapes: Archaeologies of Attachment and the Pastoral Industry in New South Wales, Department of Environment and Conservation NSW and the University of New South Wales Press, Sydney.

Hawking, Stephen and Leonard Mlodinow 2011, A Briefer History of Time, Transworld Publisher, United Kingdom.

Heaney, Seamus 1969, Door into the Dark, Faber Paperbacks, London.

Hokari, Minoru 2011, Gurindji Journey, University of New South Wales Press, Sydney.

Jones, Rhys and Neville White 1988, 'Point blank: stone tool manufacture at the Ngilipitji quarry, Arnhem Land, 1981', in, Betty Meehan and Rhys Jones (eds), Archaeology with Ethnography: An Australian Perspective, Department of Prehistory, Research School of Pacific Studies, The Australian National University, Canberra.

McGrath, Ann 2014, 'Is history good medicine', Journal of Australian Studies 38(4): 396-414.

Mulvaney, D John 1975, “The chain of connection": the material evidence', in Nicolas Peterson (ed.), Tribes and Boundaries in Australia, Australian Institute of Aboriginal Studies, Canberra: 72-94.

Paton, Rob 1994, 'Speaking through stones: a study from northern Australia', World Archaeology 26(2): 172-184.

Paton, Rob 1995, Mt Todd Mining Project, Mitigation Phase of the Aboriginal Archaeology: report on the salvage of Site MT17. A report to Zapapan NL, Sydney.

Paton, Rob 2013, 'Pelican Dreaming', deepeninghistories.anu.edu.au/sites/ pelican-dreaming/.

Price, Huw 1997, Time's Arrow and Archimedes' Point: New Directions for the Physics of Time, Oxford University Press, New York.

Read, Peter 2000, Belonging: Australians, Place and Aboriginal Ownership, Cambridge University Press, Cambridge.

Rose, Debra 1984, 'The saga of Captain Cook: morality in Aboriginal and European law', Australian Aboriginal Studies 2: 24-39.

Rose, Debra 1992, Dingo Makes Us Human: Life and Land in an Australian Aboriginal Culture, Cambridge University Press, Melbourne. 
Long History, Deep Time

Rosenberg, Daniel and Anthony Grafton 2010, Cartographies of Time, Princeton Architectural Press, New York.

Shryock, Andrew and Daniel Smail (eds) 2011, Deep History: The Architecture of Past and Present, University of California Press, Berkeley.

Smith, Mike 2013, The Archaeology of Australian Deserts, Cambridge University Press, Cambridge.

Thomson, Donald F 1949, Economic Structure and the Ceremonial Exchange Cycle in Arnhem Land, Macmillan, Melbourne.

Wolfe, Patrick 1991, 'On being woken up: the Dreamtime in anthropology and in Australian settler culture', Comparative Studies in Society and History 33: 197-224. 
This text is taken from Long History, Deep Time: Deepening Histories of Place, edited by Ann McGrath and Mary Anne Jebb, published 2015 by ANU Press, The Australian National University, Canberra, Australia. 